\title{
Pemodelan Anomali Gaya Berat Akibat Curah Hujan dan Dinamika Air Tanah di Daerah Semarang
}

\author{
Yatti Pratyas Katrinavia, Agus Setyawan, Supriyadi \\ Mahasiswa Fisika Universitas Diponegoro Semarang \\ Fisika Universitas Diponegoro Semarang \\ Fisika Universitas Negeri Semarang \\ pratyas.katrina@gmail.com
}

\begin{abstract}
Abstrak - Pemodelan ke depan (forward modelling) anomali gaya berat telah dilakukan dengan menggunakan software Grav2DC untuk mengetahui respon anomali gaya berat akibat curah hujan dan dinamika air tanah di kota Semarang. Pemodelan dilakukan dengan pendekatan model perlapisan tanah dengan parameter ketebalan dan densitas berdasarkan sayatan peta geologi. Anomali gaya berat didapatkan dari selisih g pada periode pertama dan periode kedua. Anomali gaya berat akibat curah hujan merupakan selisih besarnya presipitasi pada periode pertama dan kedua. Berdasarkan hasil pemodelan kedepan yang dibuat dapat disimpulkan bahwa akibat dinamika air tanah dapat menghasilkan perubahan gayaberat $(\Delta g)$ yang bernilai positif $(+)$ jika terdapat kenaikan air tanah dan respon anomali gaya berat bernilai negatif (-) jika terjadi penurunan air tanah. Hasil anomali gaya berat akibat perbedaan curah hujan tiap tahun menyebabkan penurunan air tanah $(\Delta h)$ sebesar 0,93 sampai 1,4 mm/tahun dengan anomali gaya berat sebesar-1,17 sampai $-1,76 \mathrm{mGal}$.
\end{abstract}

Kata kunci: pemodelan ke depan, anomali gaya berat, curah hujan, Semarang

\begin{abstract}
Grav2DC to determine the response of the gravity anomaly due to rainfall and ground water dynamics in Semarang. The Modelling is done with soil layering model approach with parameters based on the thickness and density of the geological map incision . Gravity anomaly obtained from the difference $g$ in the first period and the second period. Gravity anomaly due to a difference in the amount of rainfall precipitation in the first and second period. Based on the modeling results of the future are created can be concluded that as a result of ground water dynamics can produce changes in microgravity ( $\Delta g)$ which is positive $(+)$ if there is a rise in ground water and the response of the gravity anomaly is negative (-) if there is a decrease in ground water. The results of the gravity anomaly due to differences in annual rainfall causes a decrease in soil water ( $\Delta \mathrm{h})$ of 0.93 to $1.4 \mathrm{~mm} /$ year with the gravity anomaly of -1.17 to $-1.76 \mathrm{mGal}$.
\end{abstract}

Key words: forward modeling, gravity anomaly, rainfall precipitation, Semarang

\section{PENDAHULUAN}

Pemanfaatan air untuk memenuhi kebutuhan di semua sektor masih mengandalkan air bawah tanah sebagai bahan baku dan pasokan air bersih. Permasalahan yang terjadi adalah banyak sumur bor yang dibuat tanpa ijin dan pemanfaatannya tidak terkendali. Ref.[6] akibatnya yang terjadi di masa yang akan datang adalah rusaknya sistem akuifer yang tidak terpulihkan lagi. Dampak negatifnya antara lain penurunan muka air tanah, intrusi air laut, dan amblesan tanah. Kota Semarang diketahui mengalami amblesan tanah yang intensif setiap tahunnya dengan laju amblesan tanah yang bervariasi. [5] Dengan menggunakan metode geodetik Alos/Palsar menghasilkan laju amblesan di Semarang mencapai 15 cm/tahun pada periode 1979 - 2006. [2]Dengan menggunakan metode Insar menunjukkan laju amblesan di kota Semarang pada periode 2007 - 2009 mencapai 8 $\mathrm{cm} /$ tahun. Peristiwa amblesan tanah tersebut turut dipercepat dengan penurunan muka tanah oleh faktor kompaksi/konsolidasi batuan, penurunan muka airtanah dan pengurugan lahan Penurunan muka air tanah salah satunya dipengaruhi oleh kondisi curah hujan dan pengambilan air tanah di kota Semarang.
[9]PDAM Kota Semarang menurut baru mampu memasok 46,9\% air bersih untuk memenuhi kebutuhan penduduk, sehingga penduduk memanfaatkan air tanah dari sumur bor. Sumur bor pertama di kota Semarang dibuat pada tahun 1841, kemudian pada Tahun 1900 terdapat 16 buah sumur bor, pada Tahun 1990 menjadi 260 buah dan Tahun 2003 meningkat menjadi 1.194 buah sumur bor, sehingga selama lebih kurang 13 tahun telah terjadi peningkatan pemanfaatan air tanah dari sumur bor sebanyak $459 \%$

Penggunaan metode gaya berat telah banyak digunakan seperti [14]pemantuan injeksi air pada reservoir gas, [13]daerah reservoir panas bumi, [10] pemantuan sesar, [3]pemantuan volcano dan prediksi batuan, [2]prospek pada eksplorasi hidrokarbon

Dengan latarbelakang fenomena tersebut, maka penelitian ini memanfaatkan metode gaya berat untuk mengetahui karakteristik anomali gaya berat akibat curah hujan dan dinamika air tanah yang selalu berubah di Kota Semarang sehingga dapat diketahui daerah yang mengalami pengurangan air tanah. Pada penelitian ini karakteristik anomali gravitasi akibat dinamika perubahan air bawah tanah dan curah hujan di daerah Semarang 
dilakukan dengan tehnik forward modelling menggunakan Software Grav2DC.

\section{LANDASAN TEORI}

Anomali gayaberat mikro antar waktu disebabkan oleh beberapa hal diantaranya dinamika fluida bawah permukaan, perbedaan musim, amblesan tanah maupun perubahan topografi dan bangunan di sekitar titik amat. Persamaan anomali gayaberat antar waktu diperoleh dari "persamaan (1)" berikut

$\Delta g(x, y, z, t)=g\left(x, y, z, t_{l}\right)-g\left(x, y, z, t_{l}\right)$

"Persamaan (1) menunjukkan anomali gayaberat yang merupakan perubahan atau perbedaan nilai gayaberat terukur dalam suatu titik pada selang waktu pengukuran." [11]Jika perubahan gayaberat tidak diikuti dengan perubahan geometri dan volume sumber maka persamaan (1) dapat didekati dengan persamaan (2) berikut

$\Delta g(x, y, z, \Delta t) \approx K . \Delta \rho(x, y, z, \Delta t)$

dengan $\mathrm{K}$ adalah fungsi Green dan $\Delta \rho$ adalah kontras densitas. Berdasarkan hubungan ini, jika fungsi Green tidak mengalami perubahan, maka anomali gayaberat yang diamati sepenuhnya tergantung pada perubahan atau kontras densitas $\Delta \rho$ yang diakibatkan oleh perubahan material yang mengisi volume pori sumber anomali pada selang waktu tersebut. Jika diasumsikan pada saat $t_{1}$ semua volume pori terisi air dan pada $t_{2}$ terjadi penurunan muka air tanah, maka perubahan rapat massanya dinyatakan dengan persamaan (3),

$\Delta \rho=(1-\emptyset) \rho-[(1-\emptyset) \rho+\emptyset \rho]$

Jika persamaan (3) disubstitusikan ke dalam persamaan (2) maka akan diperoleh persamaan (4).

$\Delta g=K(-\emptyset \Delta \rho)$

"Persamaan (4) menyatakan bahwa perubahan gayaberat yang terjadi karena penurunan muka air tanah." Sebaliknya jika terjadi pengisian kembali pori batuan oleh air atau terjadi imbuhan air maka terjadi kenaikan muka air tanah. Persamaan (4) akan menjadi persamaan (5) yaitu :

$\Delta g=K(\emptyset \Delta \rho)$

Banyaknya presipitasi akan mempengaruhi perubahan ketinggian airtanah. Pada musim penghujan ketinggian airtanah akan berada pada nilai maksimum kemudian turun secara bertahap seiring dengan pergantian musim. Secara empiris persamaan penurunan eksponensial diberikan oleh "persamaan (6),"[4]untuk korelasi presipitasi dengan water level (muka air) pada persamaan (6).

$$
H(t)=H_{1}+\alpha \sum_{n} R_{n} \exp \left\{-c\left(t-t_{n}\right)\right\}
$$

dengan $\mathrm{H}_{1}$ adalah ketinggian air mula-mula, t waktu, $\mathrm{t}_{\mathrm{n}}$ waktu ke-n, $\alpha$ adalah konstanta penyerapan $(\alpha=0.00932)$, c adalah konstanta penguapan $(c=0.00985)$ dan $R_{n}$ adalah presipitasi pada bulan ke-n. Setelah didapat perubahan muka airtanah dari presipitasi, [7]maka perubahan gayaberat akibat perubahan ketinggian muka airtanah diberikan oleh "persamaan (7)" berikut :

$\Delta g=2 \pi G \phi \rho_{w} \Delta h$

dengan $\Delta \mathrm{g}$ adalah anomali gayaberat karena adanya perubahan tinggi airtanah, $\rho_{w}$ densitas air tanah $\left(\mathrm{kg} / \mathrm{m}^{3}\right)$, $\phi$ porositas dari reservoar tanah $(\%), \Delta h$ perubahan muka airtanah (meter), dan $\mathrm{G}$ konstanta gayaberat universal

\section{METODE PENELITIAN/EKSPERIMEN}

Metode yang digunakan dalam penelitian ini yakni forward modelling yang merupakan simulasi data sintetik respon anomali gayaberat antar waktu tujuannya untuk mengetahui nilai gayaberat akibat pengurangan maupun imbuhan air tanah. Pemodelan anomali gaya berat pada penelitian ini juga didasarkan pada perubahan curah hujan yang terjadi tiap tahun dengan menggunakan "persamaan (6)," dan "persamaan (7)". [13]Model dibuat berdasarkan peta geologi lembar Magelang - Semarang.

\section{HASIL DAN PEMBAHASAN}

Pada penelitian ini dibuat tiga model yaitu model awal, model penurunan muka air tanah dan model kenaikan muka air tanah. Model ini berbentuk 2D yang dibuat menggunakan software Grav2DC. Model awal merupakan model yang diasumsikan belum mengalami penurunan dan kenaikan. Model kedua adalah penurunan muka air tanah sebesar $10 \mathrm{~m}$ dan imbuhan $5 \mathrm{~m}$. Simulasi dilakukan dengan membuat model bumi 3 lapis yang memanjang ke arah horizontal.[8]Lapisan 1 berupa batuan alluvial dengan rapat massa $1,9 \mathrm{gr} / \mathrm{cm}^{3}$ memiliki ketebalan $10 \mathrm{~m}$, pada kedalaman $10 \mathrm{~m}$ hingga $50 \mathrm{~m}$ terdapat lapisan pasir yang merupakan akuifer dengan $\rho=$ 2,0 $\mathrm{gr} / \mathrm{cm}^{3}$. Porositas akuifer $30 \%$, dan lapisan ketiga berupa lempung dengan $\rho=2,1 \mathrm{gr} / \mathrm{cm}^{3}$

Pada "gambar.1" menunjukkan model respon gayaberat akibat penurunan muka air tanah sebesar $10 \mathrm{~m}$. Rapat massa pada saat $\mathrm{t}_{1}$ dan $\mathrm{t}_{2}$ masing-masing adalah 2,1 $\mathrm{gr} / \mathrm{cm}^{3}$ dan $2,0 \mathrm{gr} / \mathrm{cm}^{3}$. Diasumsikan penurunan muka air tanah terjadi pada koordinat $20-80 \mathrm{~m}$. Hasil simulasi menunjukkan bahwa pengurangan air tanah akan memberikan nilai gradien vertikal gayaberat mikro antar waktu bernilai negatif.

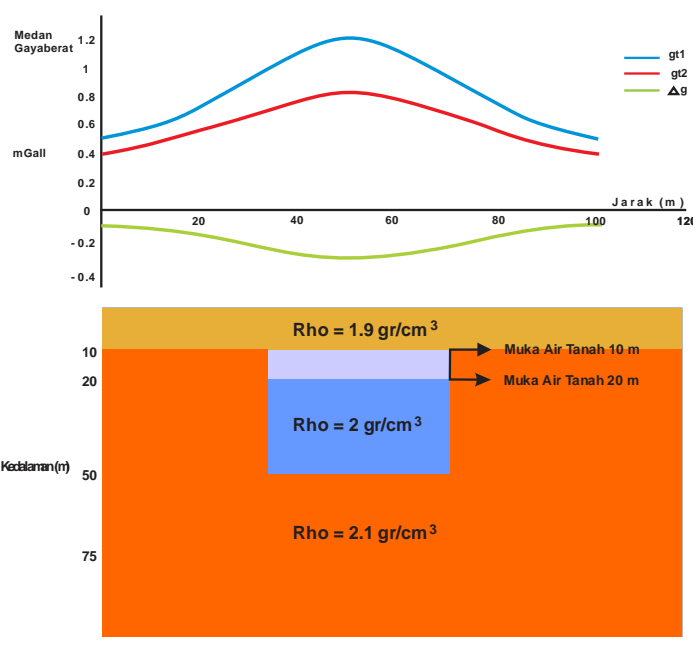

Gambar 1. Karakteristik anomali gayaberat akibat pengurangan air tanah

Pengisian kembali air tanah pada akuifer menyebabkan kenaikan rapat massa akuifer yang besarnya tergantung pada porositas dan saturasi akuifer air tanah tersebut. Model fisis yang digunakan sama dengan model fisis pengurangan air tanah. Pada "gambar.2" menunjukkan 
model respon gayaberat akibat imbuhan air tanah sebesar $5 \mathrm{~m}$. Rapat massa pada saat $\mathrm{t}_{1}$ dan $\mathrm{t}_{2}$ masing-masing adalah 2,1 $\mathrm{gr} / \mathrm{cm}^{3}$ dan $2,0 \mathrm{gr} / \mathrm{cm}^{3}$. Hasil simulasi menunjukkan bahwa imbuhan air tanah akan memberikan anomali gayaberat bernilai positif.
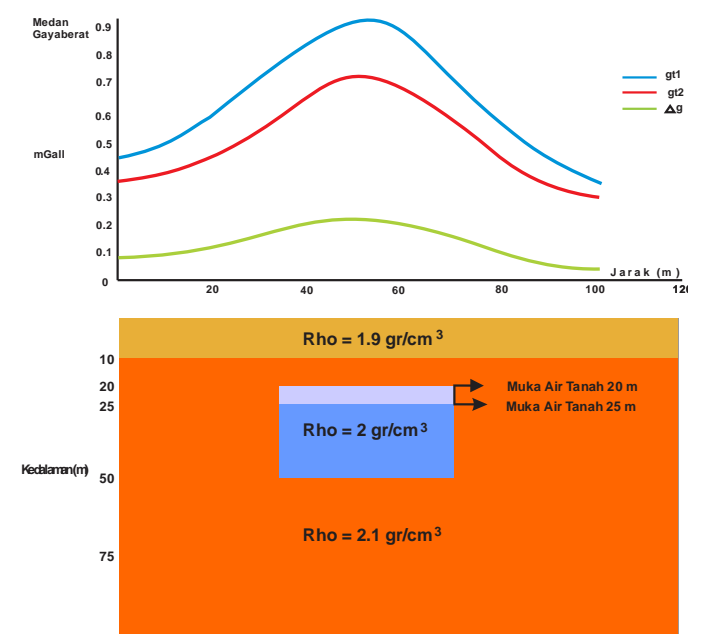

Gambar 2. Karakteristik anomali gayaberat akibat imbuhan air tanah

Dari data curah hujan pada tabel.1 menunjukkan bahwa musim hujan terjadi pada bulan Mei dan musim kemarau terjadi pada bulan Oktober.

Tabel 1. Data Curah Hujan (BMKG, 2015)

\begin{tabular}{cccccc}
\hline & 2010 & 2011 & 2012 & 2013 & 2014 \\
\hline Mei & 247.6 & 150 & 173 & 131.1 & 134.1 \\
Oktober & 238 & 65 & 187.3 & 69.1 & 22.1 \\
\hline Dengan & menggunakan & "persamaan & (6)," & dapat
\end{tabular}
dilakukan pendekatan empiris untuk hubungan presipitasi dengan perubahan ketinggian muka airtanah. Nilai $\left(\mathrm{H}_{1}\right)$ untuk keadaan awal dianggap nol. Sehingga kita mendapatkan nilai $\Delta \mathrm{h}$ dari pendekatan empiris adalah $0,93 \mathrm{~mm}$. Kemudian $\Delta \mathrm{g}$ akibat perubahan ketinggian airtanah dapat dihitung dengan menggunakan "persamaan (7)". Hasil anomali gaya berat akibat perbedaan curah hujan tiap tahun mengalami penurunan dengan $\Delta \mathrm{g}$ sebesar $-1,17 \mathrm{mGal}$ pada saat musim penghujan dan $\Delta \mathrm{g}$ sebesar $-1,76$ mGal pada saat musim kemarau. Seperti terlihat pada "gambar.3."

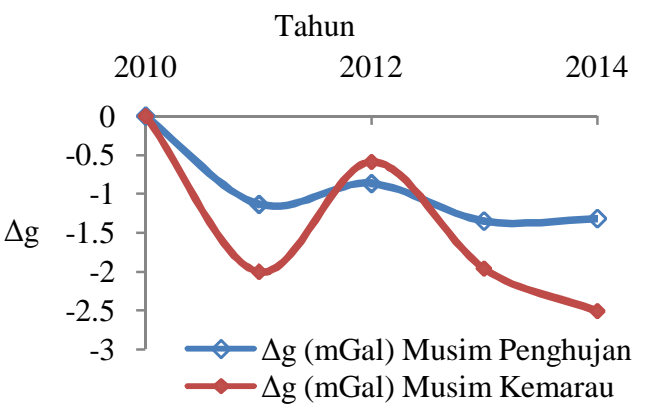

Gambar 3. Karakteristik anomali gayaberat akibat perubahan curah hujan.

\section{KESIMPULAN}

Dari hasil pemodelan kedepan yang dibuat dapat disimpulkan bahwa akibat dinamika air di dalam tanah dapat menghasilkan perubahan gayaberat $(\Delta \mathrm{g})$. Jika terdapat kenaikan air tanah akan menunjukkan respon anomali gaya berat positif dan jika terjadi penurunan air tanah akan menunjukkan respon anomali gaya berat negatif tetapi jika tidak terjadi keduanya maka anomali gaya berat samadengan nol. Hasil anomali gaya berat akibat perbedaan curah hujan tiap tahun mengalami penurunan air tanah $\Delta \mathrm{h}$ sebesar 0,93 sampai 1,4 $\mathrm{mm} /$ tahun dengan anomali gaya berat sebesar $-1,17$ sampai $-1,76 \mathrm{mGal}$.

\section{PUSTAKA}

[1] Anita Yuliyanti, Dwi Sarah, Eko Soebowo, Pengaruh Lempung Ekspansif Terhadap Potensi Amblesan Tanah di Daerah Semarang, Riset Geologi dan Pertambangan, vol. 22, no. 2, 2012, pp. 93-103.

[2] Ashar M., Toshinori S., Nobuhiro T., Nobuhiro I., Tsutomu Y., Ground subsidence in Semarang-Indonesia investigated by ALOS-PALSAR satellite SAR interferometry, Journal of Asian Earth Sciences, 2011, vol. 40

[3] B.S.Badmus, N.K Sotona, Krieger, Gravity Support for Hydrocarbon Exploration at the Prospect Level. Journal of Emerging Trends in Engineering and Applied Sciences, 2011, vol. 2 , pp.1-6.

[4] Chitoshi Akasaka and Shigetaka Nakanishi, Correction Of Background Gravity Changes Due To Precipitation:Oguni Geothermal Field, Japan,Proceedings World Geotherma Congress, 2000, pp. 2471-2475

[5] Hasanuddin. Z, Abidin. H, Teguh Irwan P.S,Fukuda, Gamal, Heri A., Murdohardono, Supriyadi. Studying Land Subsidence in Semarang (Indonesia) Using Geodetic Methods. FIG Congress IUGG General Assembly. 2010

[6] Hendrayana, H. 2002. Dampak Pemanfaatan Air Tanah. Universitas Gadjah Mada, Yogyakarta, 2002.

[7] Hunt, T., Microgravity Measurements At Wairakei Geothermal Field, New Zealand; A Review Of 30 Years Data (1961-1991). Taupo: Wairakei Research Centre, Institute of Geological \& Nuclear Science. 2000.

[8] Marsudi, Prediksi laju amblesan tanah di dataran alluvial Semarang provinsi Jawa Tengah. Jurusan pertambangan ITB, Bandung, 2011.

[9] Putranto T.T. \& Rüde T.R, Groundwater Problems in Semarang Demak Urban Area, Java/Indonesia. RWTH Aanchen University. Jerman , 2011.

[10] Reza Toushmalani, 2010. Application of Gravity Method in Fault Path Detection. Australian Journal of Basic and Applied Sciences. vol 4. pp. 2450-2460.

[11] Setianingsih, Rustan E., Wawan GA. Kadir, Djoko S., Chalid IA, Susanti A,. Gravity gradient technique to identify fracture zones in Palu Koro strike slip fault. Procedia Enviromental Sciences, 2013, vol.17

[12] Sumadirja H, 1996, Peta geologi Lembar Magelang dan Semarang Jawa Tengah. Pusat Survei Geologi, Bandung

[13] Yayan. S, Yunus. D, Jun Nishijima, Y. Fujimitsu, Yustin K, Ahmad Yani, Y. Fukuda, Makoto Taniguchi. The first repeated absolute gravity measurement for geothermal monitoring in the Kamojang Geothermal Field Indonesia. Journal Geothermics. 2015, vol 53, pp.114-124.

[14] Zuhdi, Sismanto. Response of Time Lapse Gravity Anomaly Model of Gas Injection in Reservoir and Water Table Changes on it's Near Surface. The Third Basic Science International Conference.2013, vol.6, pp.1-5. 